\title{
Cutaneous Lymphangioma Secondary to Breast Cancer Radiotherapy after Mastectomy: A Case Report
}

Safoura Shakoei ${ }^{1}$, maryam Noorbakhsh Sabet ${ }^{1}$, and Alireza Ghanadan ${ }^{1}$

${ }^{1}$ Tehran University of Medical Sciences

December 14, 2021

\begin{abstract}
We report a case of cutaneous lymphangioma secondary to breast cancer radiotherapy after mastectomy.

\section{Hosted file}

clinical case report.docx available at https://authorea.com/users/451070/articles/549324cutaneous-lymphangioma-secondary-to-breast-cancer-radiotherapy-after-mastectomy-a-casereport
\end{abstract}

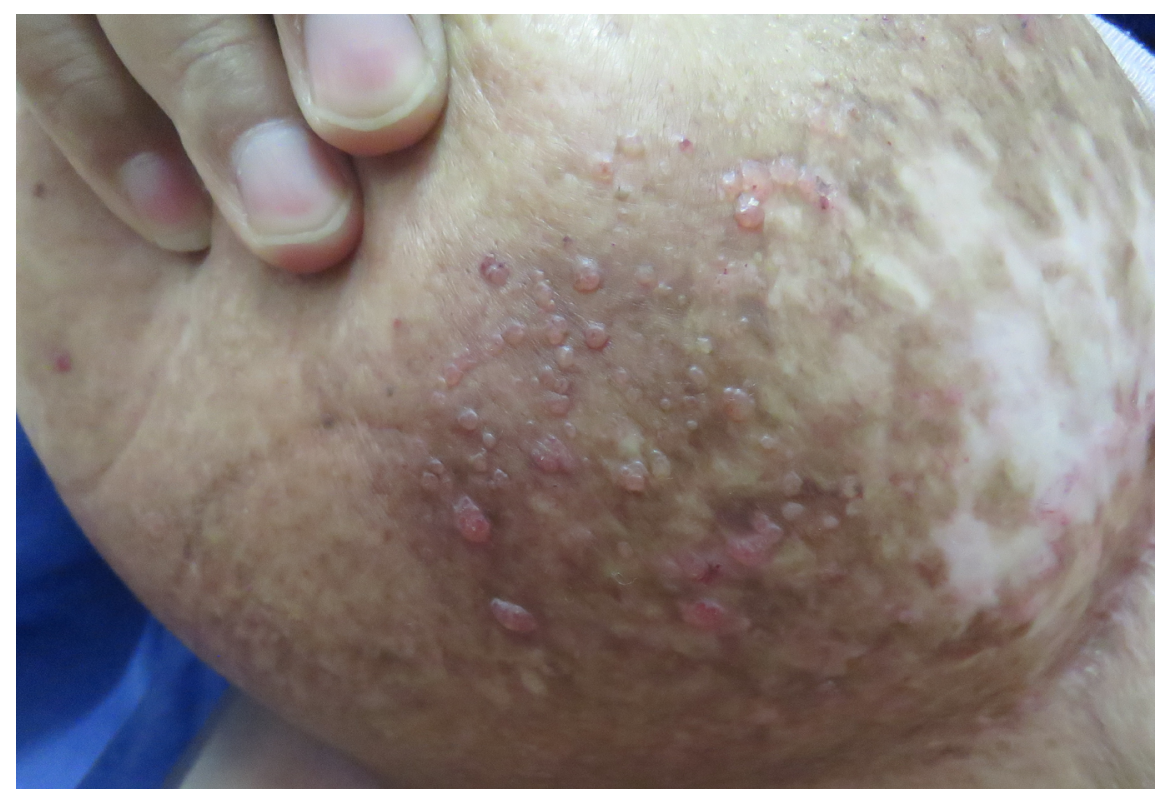




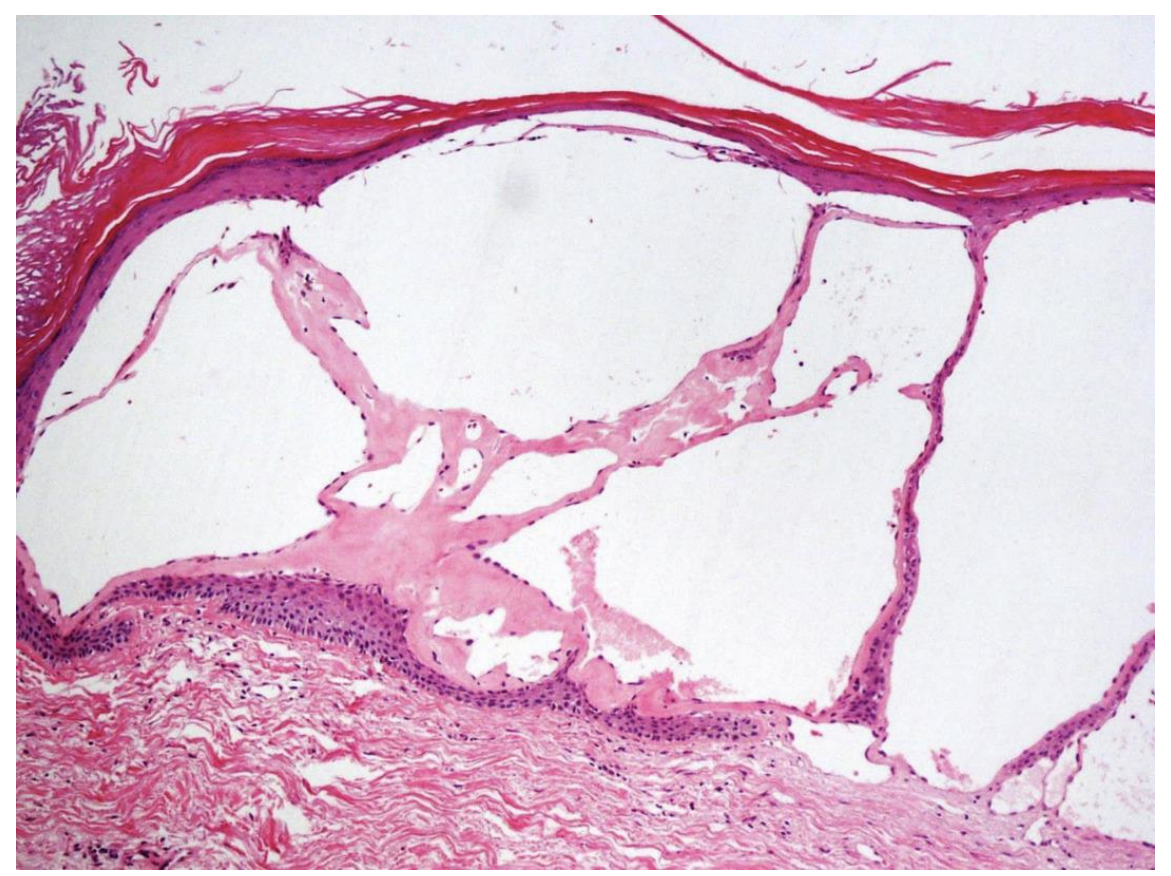

